\title{
CONDUCTIVITY PROPERTIES OF THIOUREA- AND UREA-HALOGEN INCLUSION COMPOUNDS WITH DIQUINUCLIDINIUM CATION AS GUEST
}

\author{
JUAN MERCHAN ${ }^{2}$,VLADIMIR LAVAYEN ${ }^{1}$, PAUL JARA ${ }^{1}$, VICTOR SANCHEZ ${ }^{3}$, NICOLAS YUTRONIC * \\ ${ }^{1}$ Departamento de Química, Facultad de Ciencias, Universidad de Chile \\ Casilla 653, Santiago, Chile \\ ${ }^{2}$ Departamento de Química, Universidad Tecnológica Metropolitana, Casilla 9845, Santiago, Chile \\ ${ }^{3}$ Departamento de Química, Facultad de Ciencias, Universidad Católica del Norte, Casilla 1280, Antofagasta, Chile \\ (Dedicated in memory of our colleague and friend Prof. Dr. Jaime Retuert) \\ (Received: 29 November 2007 - Accepted: 26 March 2008)
}

\begin{abstract}
Thiourea and urea can modify their typical host properties to form new ternary polymolecular anionic halogen hosts in which the diquinuclidinium cation is included. A comparative study of the proton conductivity properties of this kind of inclusion compounds is presented. The hexagonal binary inclusion compound [quinuclidine $]_{3}$, thiourea $\mathbf{1}$ was taken as reference. The study shows the conductivity properties of [quinuclidine $\left.{ }_{2} \mathrm{H}\right]^{+}\left[\mathrm{thiourea}_{2} \mathrm{Cl}\right]^{-} \mathbf{2}$, [quinuclidine $\left.{ }_{2} \mathrm{H}\right]^{+}\left[\text {thiourea }_{2} \mathrm{Br}\right]^{-}$ 3, [quinuclidine $\left.{ }_{2} \mathrm{H}\right]_{2}^{2+}\left[\text { thiourea }_{2} \mathrm{I}_{2}\right]^{2-4}$, [quinuclidine $\left.{ }_{2} \mathrm{H}\right]^{+}\left[\text {urea }_{5} \mathrm{Cl}^{-} \mathbf{5} \text {, [quinuclidine }{ }_{2} \mathrm{H}\right]^{+}\left[\text {urea }_{2} \mathrm{Br}\right]^{-} \mathbf{6}$, and [quinuclidine $\left.{ }_{2} \mathrm{H}\right]^{+}\left[\text {urea }_{2} \mathrm{I}\right]^{-7}$. Ionic conductivities of all the compounds in pellets, and of $\mathbf{2}$ and $\mathbf{3}$ in large single crystals were measured by electrochemical impedance spectroscopy (EIS). Anisotropic conductivity behaviour in crystals of adequate dimensions of $\mathbf{2}$ and $\mathbf{3}$ was detected. The conductivity values of $\mathbf{2}$ and $\mathbf{3}$ in the crystals were $2.19 \times 10^{-4}$ and $6.03 \times 10^{-6}(\mathrm{~S} / \mathrm{cm})$, respectively, in the assumed channel direction, and $2.42 \times 10^{-6}$ and $8.27 \times 10^{-9}(\mathrm{~S} / \mathrm{cm})$, respectively, in the perpendicular direction to the former, at $298 \mathrm{~K}$. Conductivities at room temperature of the thiourea-halide derivatives in pellets show a changing behaviour from insulator $\left(10^{-11} \mathrm{~S} / \mathrm{cm}\right)$ for $\mathbf{2 , 3}$ and $\mathbf{4}$ measured in vacuum, to semiconductor $\left(10^{-7}-10^{-8} \mathrm{~S} / \mathrm{cm}\right)$ for the thiourea-halide derivative measured at atmospheric pressure. For the urea-halide system the highest conductivity value corresponds to derivative $7\left(8.66 \times 10^{-5} \mathrm{~S} / \mathrm{cm}\right)$ at atmospheric pressure, and the lowest to derivative $5\left(5.48 \times 10^{-7} \mathrm{~S} / \mathrm{cm}\right)$ measured in vacuum. Comparisons considering structural aspects are also discussed.
\end{abstract}

Keywords: conductivity properties, supramolecular compounds, ternary urea and thiourea inclusion compounds,

\section{INTRODUCTION}

Inclusion compounds are suitable systems for investigating the nature of molecular guest-host interactions and for calling attention to their applications in electronics and optoelectronics. ${ }^{1-3}$ Host materials such as urea, thiourea, cyclodextrins, calixarenes, zeolites, and perhydrotriphenylene allow the formation of specific host-guest architectures, where guest molecules are incorporated along channels, within layers, or in isolated cages. ${ }^{4-6}$ Among such materials, urea and thiourea inclusion compounds have received particular attention. X-ray diffraction studies have shown that the typical binary compounds of urea and thiourea are built with a hexagonal channel structure. ${ }^{1}$ 4, 7-9 Indeed, guest species containing amino or azacyclo functional groups are also included in urea and thiourea hosts., 5, 10-14 Using 1,2-diazabicyclo[2.2.2] octane, or hexamethylenetetramine as guest and thiourea as host, it has been possible to obtain binary layered inclusion compounds. ${ }^{14,15}$

Urea and thiourea hosts are formed by hydrogen bonding and they can include a variety of guest molecules of appropriate size and shape. The small urea channels are appropriate for storing non-branched hydrocarbon chains, for example, while the thiourea channels are appropriate for storing branched hydrocarbon chains. ${ }^{1,5}$ The synthesis of new ternary compounds offers the possibility of obtaining derivatives of urea and thiourea matrices containing channels of sufficient size to accommodate bulky molecules, and it will also be interesting to study the conductivity properties of cationic guests. Ternary complexes of urea and thiourea are very limited., ${ }^{2,3}, 7-10,14,16-19$ Quinuclidine (1-azabicyclo[2.2.2] octane) as guest has a small cyclic structure with basic properties. The proton affinity of quinuclidine is $236 \mathrm{kcal} / \mathrm{mol}$, and the threedimensional model with space occupation indicates that there is no strain energy as in other pyramidal nitrogen compounds like triethylamine. ${ }^{20}$

Anisotropic conducting materials will be of interest to study their potential in the development of more efficient devices in the fields of microelectronics and communications, for example. Looking for compounds relevant to such applications it is possible to obtain ordered solids as oriented phases or as single crystals of appropriate size. ${ }^{3}$ Molecular engineering as well as chemical recognition and the formation of small size inclusion compounds have often shown to be appropriate methods for achieving ordered phases. ${ }^{1}$

In this paper we report the differences in ionic conductivity of the following compounds previously synthesized by us, and the determination of their structural properties: [quinuclidine] [thiourea] ${ }_{3} \mathbf{1}^{\text {tc }}$, [quinuclidine $\left.{ }_{2} \mathrm{H}\right]^{+}[$thio urea ${ }_{2} \mathrm{Cl}^{-} \mathbf{2},{ }^{3 \mathrm{c}}$ [quinuclidine $\left.{ }_{2} \mathrm{H}\right]^{+}\left[\right.$thiourea $\mathrm{Br}_{2} \mathbf{3}^{3},{ }^{19}$ [quinuclidine $\mathrm{H}_{2}{ }_{2}{ }_{2}^{2+}\left[\right.$ thiourea $_{2} \mathrm{I}$ $\left.{ }_{2}\right]^{2-4} \mathbf{4}^{2}{ }^{19}$ [quinuclidine $\left.{ }_{2} \mathrm{H}\right]^{+}\left[\text {urea }_{5} \mathrm{Cl}\right]^{-} \mathbf{5}^{1 \mathrm{~b}}{ }^{\mathrm{b}}$ [quinuclidine $\left.{ }_{2} \mathrm{H}\right]^{+}\left[\mathrm{urea}_{2} \mathrm{Br}\right]^{-} \mathbf{6}^{2 \mathrm{c}}$ and [qui nuclidine $\left.{ }_{2} \mathrm{H}\right]^{+}\left[\text {urea }_{2} \mathrm{I}\right]^{-} 7^{2 \mathrm{c}}$ The aim of this work was also to study the existence of electric transport features in these crystalline compounds.

We found that there are four kinds of structures, shown in Figure 1. The first corresponds to a typical channel inclusion compound, like $\mathbf{1}$; the second corresponds to ionic ternary channel inclusion compounds, like $\mathbf{2}$ and $\mathbf{3}$; the third corresponds to layered ionic ternary inclusion compounds, like $\mathbf{4 , 6}$ and 7; and the fourth corresponds to a bi-channel ionic ternary inclusion compound, characteristic of 5 .
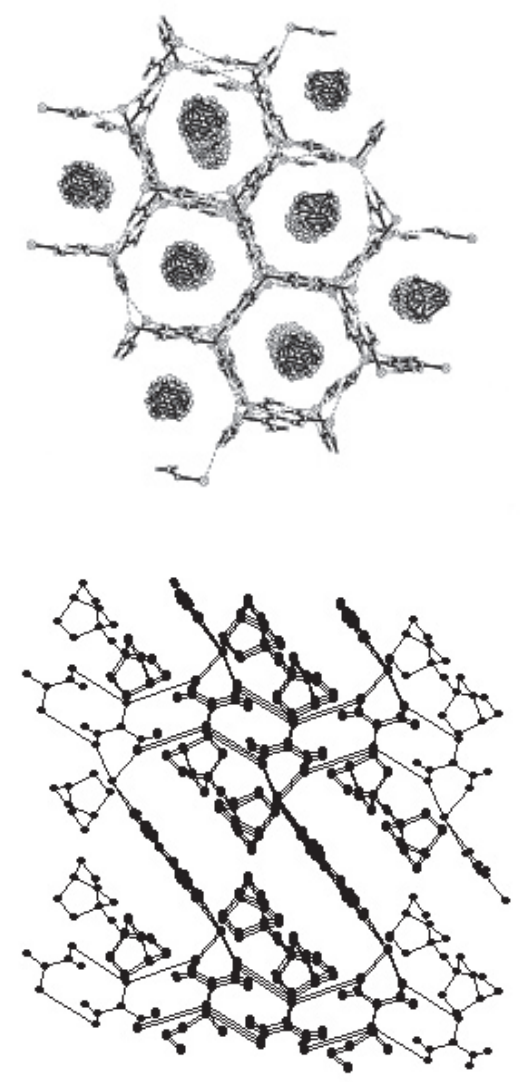

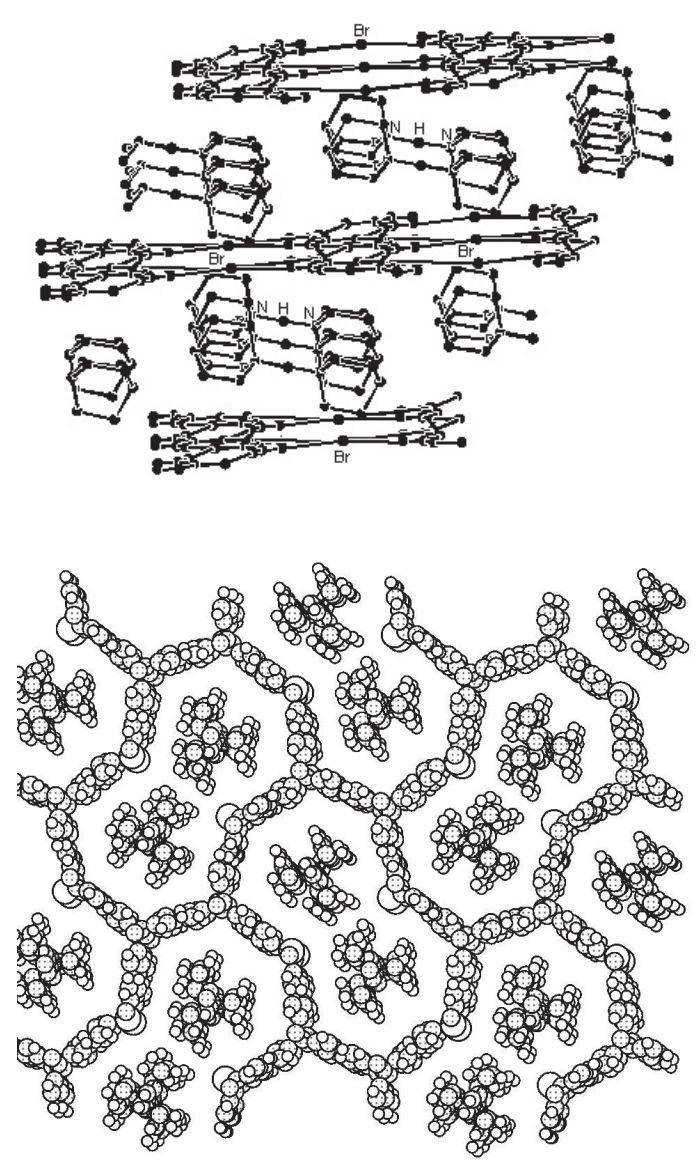

Figure 1a: Channels of the matrix $\mathrm{TU}_{3} \mathrm{Q} 1$ for 3 .

$1 \mathrm{~b}$ : Structure of the compound $\mathrm{Tu}_{2}\left[\mathrm{Q}_{2} \mathrm{H}\right]^{+} \mathrm{Cl}^{-} \mathbf{2}$. This structure is analogue

1c: Layer structure of Urea [quinuclidine $\mathrm{H}_{2}{ }^{+} \mathrm{Br}$ 6. Diquinuclidinium ions are sandwiched between the host layers of parallel hydrogen bonded urea ribbons cross-bridged by $\mathrm{Br}^{-}$and $\mathrm{I}^{-}$( for 7 ) anions.

1d: Bichannel structure of the compound Urea ${ }_{5}\left[\mathrm{Q}_{2} \mathrm{H}\right]^{+} \mathrm{Cl}^{-5}$

\section{EXPERIMENTAL PART}

Electric conductivities were measured by AC-impedance analysis in the 1-105 $\mathrm{Hz}$ range (PARC Electrochemical Impedance Analyser model 6310). Approximately $0.1 \mu \mathrm{m}$ thick gold layers evaporated onto both sides of the crystal or pellet were provided as electrical contacts. Robust enough single crystal specimens (the size of one of compound 2, for example, was $2.6 \mathrm{~mm} \mathrm{x}$ $2.1 \mathrm{~mm} \times 1.3 \mathrm{~mm}$ ) were obtained by including the crystal in a block of an epoxy resin, leaving uncovered only those sides used for the electrical contacts, both faces parallel to the crystal direction, and the parallel terminal faces. Figure 2 shows a typical crystal used for the measurements. Polycrystalline pellets were obtained by compressing the powder in a 6-mm diameter cylindrical die under a pressure of $10.2 \mathrm{MPa}$. The instrument's measurement error was $10^{-11} \mathrm{~S}$. Figure 3 shows schematically the connection between the crystals or pellets and the impedance system.

Conductivities were measured at room temperature in vacuum and at atmospheric pressure.

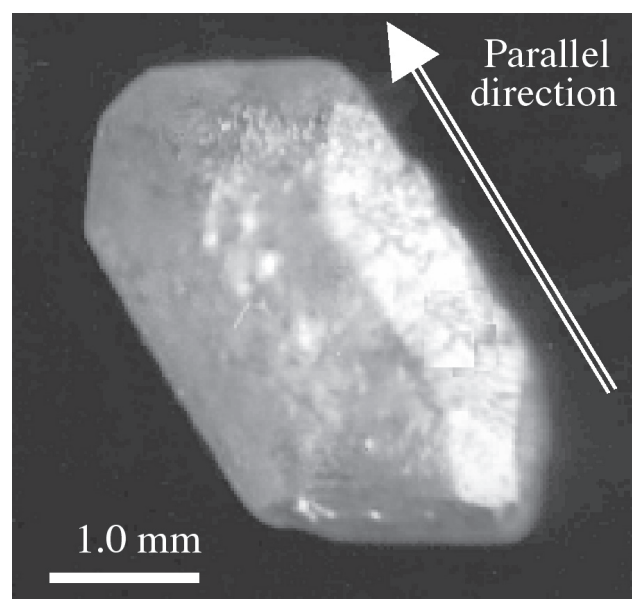

Figure 2: Optical image of crystal compound $\mathrm{Tu}_{2}\left[\mathrm{Q}_{2} \mathrm{H}\right]^{+} \mathrm{Cl}^{-}$and the orientation of the pressed samples for the electrical measurements.

\section{RESULTS AND DISCUSSION}

\section{Thiourea-Halogen System}

The inclusion compound [quinuclidine], [thiourea] $\mathbf{1}$ was taken as reference for this study. In this compound the matrix has a channel structure the guest occupies the crystallographic position of the $c$ axis and shows high thermal agitation in the channel (Figure 1a). The guest is not ionic and offers no possibility for proton motion. As expected, this compound behaves as an insulator.

Structures $\mathbf{2}$ and $\mathbf{3}$ have an iso-structural relation between each other, Table 1 . The dimensions of the crystallographic lattice are very similar, and the differences between them depend only on the volume of the halogen. The anionic matrices of compounds $\mathbf{2}$ and $\mathbf{3}$ are formed by chains of thiourea molecules bonded through hydrogen bridges forming helicoidal channels, (Figures $1 \mathrm{~b}$ and 4 ). These chains are bonded together by the halogen ions, forming part of the anionic channels, where the diquinuclidinium counter-ion $\left[\mathrm{Q}_{2} \mathrm{H}\right]^{+}$is accommodated in the matrix channels. In the structures of $\mathbf{2 , 3}$ and 4 the thiourea molecules interact with each other via $\mathrm{N}-\mathrm{H} \cdots \mathrm{S}$ hydrogen bonds to produce ribbon-like arrangements. In structures $\mathbf{2}$ and $\mathbf{3}$ these ribbons do not contain the halogen directly and define two non intersecting sets running along the $a$ and $b$ axes, linked through $\mathrm{N}-\mathrm{H} \cdots \mathrm{Cl}$ and $\mathrm{N}-\mathrm{H} \cdots \mathrm{Br}$ hydrogen bonds, respectively, with the external halide ions as acceptors. These ribbon-crossovers define the channel structure along $c$ with a cavity of ca. 9.6x13.4 $\AA$ for 2 and $5.85 \times 15.50 \AA$ for 3 , in which the $\left[\mathrm{Q}_{2} \mathrm{H}\right]^{+}$complex species are stacked with a periodicity of $11.3 \AA$ in $\mathbf{2}$ and $11.4 \AA$ in $\mathbf{3}$. The guest species $\left[\mathrm{Q}_{2} \mathrm{H}\right]^{+}$corresponds to an adduct of a heterocyclic base with a conjugated cation in a $[\mathrm{Q} \cdots \mathrm{H} \cdot \mathrm{\textrm {Q }}]^{+}$ symmetric linear arrangement similar to one reported for diquinuclidinone. ${ }^{21}$

Table 1: Space groups and stoichiometry ratios of the urea- and thioureahalogen inclusion compounds.

\begin{tabular}{|c|c|c|c|c|c|}
\hline & C.I & $\begin{array}{c}\text { Relation } \\
\text { H:G:A }\end{array}$ & A & Morphology & $\begin{array}{l}\text { Space } \\
\text { Group }\end{array}$ \\
\hline 1 & $\mathrm{Tu}_{3} \mathrm{Q} 1$ & $3: 1: 0$ & --- & Channel & $\mathrm{R}-3 \mathrm{c}^{4 \mathrm{c}}$ \\
\hline 2 & $\mathrm{Tu}_{2}\left[\mathrm{Q}_{2} \mathrm{H}\right]^{+} \mathrm{Cl}^{-} \mathbf{2}$ & $2: 1: 1$ & Chloride & Channel & $\underline{\mathrm{C} 2 / \mathrm{c}^{3 \mathrm{c}}}$ \\
\hline 3 & $\mathrm{Tu}_{2}\left[\mathrm{Q}_{2} \mathrm{H}\right]^{+} \mathrm{Br} \mathbf{3}$ & $2: 1: 1$ & Bromide & Channel & $\underline{\mathrm{C} 2 / \mathrm{c}^{19}}$ \\
\hline 4 & $\mathrm{Tu}_{9}\left[\mathrm{Q}_{2} \mathrm{H}_{2}\right]_{2}^{+} \mathrm{I}_{2}^{-\mathbf{4}}$ & $9: 2: 2$ & Iodide & Layer & $\mathrm{P} 1^{19}$ \\
\hline 5 & $\mathrm{U}_{5}\left[\mathrm{Q}_{2} \mathrm{H}^{+} \mathrm{Cl}^{-} \mathbf{5}\right.$ & $5: 1: 1$ & Chloride & Bichannel & $\underline{P c} \underline{\underline{1 b}}$ \\
\hline 6 & $\mathrm{U}_{2}\left[\mathrm{Q}_{2} \mathrm{H}\right]^{+} \mathrm{Br} \mathbf{6}$ & $2: 1: 1$ & Bromide & Layer & $\underline{\mathrm{C} 2^{2 \mathrm{c}}}$ \\
\hline 7 & $\mathrm{U}_{2}\left[\mathrm{Q}_{2} \mathrm{H}\right]^{+} \mathrm{I}^{-} 7$ & $2: 1: 1$ & Iodide & Layer & $\mathrm{C} 2^{2 \mathrm{c}}$ \\
\hline
\end{tabular}

C.I $=$ Inclusion Compounds $\quad H=$ Host $G=$ Guest $\quad A=$ Halide 


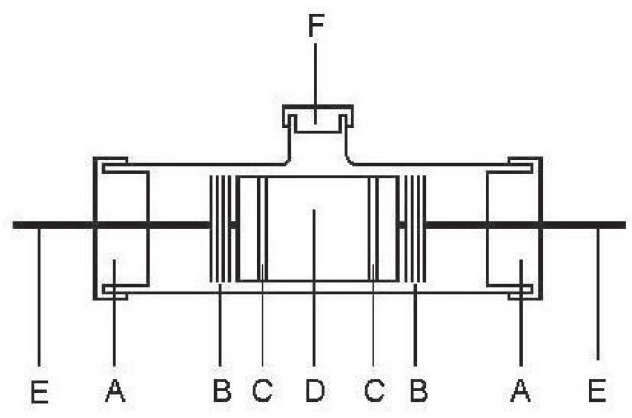

\section{Scheme of a symmetrical cell with electrodes blockers of ions}

\section{A: Stopper of latex \\ B: Metallic springs \\ C: Golden layer \\ D: Sample \\ E: Terminals (connection to the team of impedance) \\ F: Stopper of latex (connectior vacuum -argon)}

Figure 3: Schema of the used impedance system.

In structure 4, ribbons contain iodide anions as well as bridging thiourea dimers forming parallel 1D structures which align their flat side parallel to the (110) set of planes, leaving a free space of ca. $8.25 \AA$. Beside the omnipresent coulombic forces due to the ionic character of the structure, the only other interactions holding the cationic groups seem to be van der Waals forces, as suggested by the distances between the outermost hydrogen in the diquinuclidinium complex and the matrix, which are longer than $3 \AA$.

For the conductivity measurements in single crystals under atmospheric pressure, the direction of the largest axis of the unit cell was defined as the parallel direction, and also taking into account macroscopic observations like the crystals' preferential direction of growth and the experimental criterion of the visual dynamic effect observed for dissolution of crystals, ${ }^{5 b}$ which occurs also in this preferential direction, Figure 2.

For compounds $\mathbf{2}$ and $\mathbf{3}$ it was possible to measure the conductivities in the crystal itself (Table 2) in the parallel and perpendicular directions (Figure 2). Conductivity values in the parallel direction were higher that those in a perpendicular direction, $2.19 \times 10^{-4}$ and $2.4 \times 10^{-6} \mathrm{~S} / \mathrm{cm}$, respectively, for 2 , and $6.03 \times 10^{-6}$ and $8.27 \times 10^{-9} \mathrm{~S} / \mathrm{cm}$, respectively, for 3 . However, the conductivity ratios $\left(\sigma_{\|} / \sigma_{\perp}\right)$ for $\mathbf{2}$ and $\mathbf{3}$ had values of 91 and 729 , respectively, at $298 \mathrm{~K}$.

Table 2: Conductivity values of the pressed powders of urea-halogen and thiourea-halogen systems.

\begin{tabular}{|c|c|c|c|c|c|}
\hline \multirow{2}{*}{ C.I. } & \multicolumn{2}{c|}{ Pellets* } & \multicolumn{2}{c|}{ Monocrystal } \\
\cline { 3 - 6 } & $\begin{array}{c}\text { Atm } \\
(\mathrm{S} / \mathrm{cm})\end{array}$ & $\begin{array}{c}\text { Vac } \\
(\mathrm{S} / \mathrm{cm})\end{array}$ & $\begin{array}{c}1 \mathrm{Atm} \\
(\mathrm{S} / \mathrm{cm})\end{array}$ & $\begin{array}{c}\perp \mathrm{Atm} \\
(\mathrm{S} / \mathrm{cm})\end{array}$ \\
\hline $\mathbf{1}$ & $\mathrm{Tu}_{3} \mathrm{Q}$ & $2.63 \times 10^{-11}$ & $1.68 \times 10^{-11}$ & --- & --- \\
\hline $\mathbf{2}$ & $\mathrm{Tu}_{2}\left[\mathrm{Q}_{2} \mathrm{H}\right]^{+} \mathrm{Cl}^{-}$ & $1.48 \times 10^{-8}$ & $4.20 \times 10^{-11}$ & $2.19 \times 10^{-4}$ & $2.42 \times 10^{-6}$ \\
\hline $\mathbf{3}$ & $\mathrm{Tu}_{2}\left[\mathrm{Q}_{2} \mathrm{H}\right]^{+} \mathrm{Br}$ & $1.05 \times 10^{-8}$ & $4.82 \times 10^{-11}$ & $6.03 \times 10^{-6}$ & $8.27 \times 10^{-9}$ \\
\hline $\mathbf{4}$ & $\mathrm{Tu}_{2}\left[\left(\mathrm{Q}_{2} \mathrm{H}\right)^{+}\right]_{2}(\mathrm{I})_{2}$ & $1.36 \times 10^{-7}$ & $3.73 \times 10^{-11}$ & --- & --- \\
\hline $\mathbf{5}$ & $\mathrm{U}_{5}\left[\mathrm{Q}_{2} \mathrm{H}\right]^{+} \mathrm{Cl}$ & $4.00 \times 10^{-6}$ & $5.48 \times 10^{-7}$ & --- & --- \\
\hline $\mathbf{6}$ & $\mathrm{U}_{2}\left[\mathrm{Q}_{2} \mathrm{H}\right]^{+} \mathrm{Br}$ & $1.19 \times 10^{-5}$ & $1.13 \times 10^{-7}$ & --- & --- \\
\hline $\mathbf{7}$ & $\mathrm{U}_{2}\left[\mathrm{Q}_{2} \mathrm{H}\right]^{+} \mathrm{I}$ & $8.66 \times 10^{-5}$ & $2.58 \times 10^{-6}$ & --- & --- \\
\hline
\end{tabular}

*All the values of the conductivities are measurements at room temperature

$\mathrm{Atm}=$ atmospheric pressure. Vac $=$ Vacuum

Although the bridging proton in $\left[\mathrm{Q}_{2} \mathrm{H}\right]^{+}$in $\mathbf{2}$ and $\mathbf{3}$ appears to be located in the crystallographic symmetry centre, it shows a rather high thermal motion, with the largest principal axis making a $150^{\circ}$ angle to the N-N direction. The mean square root displacement of the proton along the hydrogen bond axis is indicative of a disordered arrangement with two closely spaced sites for bridged hydrogen. Such a dual location for the proton is indeed predicted by ab initio calculation of the $\left[\mathrm{NH}_{3}-\mathrm{H}-\mathrm{NH}_{3}\right]^{+}$complex, from which the existence of a double well potential for proton transfer is deduced. ${ }^{22}$ Furthermore, a vibrational analysis prediction of this hypothetical species shows infraredactive vibrational mode absorptions at $668 \mathrm{~cm}^{-1}$ for the symmetric $\mathrm{N} \cdots \mathrm{N}$ stretching mode, and at 2798 and $1260 \mathrm{~cm}^{-1}$ for the vibrational anti-symmetric transfer. ${ }^{22,23}$ Similar features are indeed observed in the IR vibrational spectra of $\left[\mathrm{Q}_{2} \mathrm{H}\right]^{+}$, where in the low frequency region a continuum threshold appears at $550 \mathrm{~cm}^{-1}$. Another characteristic frequency at $2937 \mathrm{~cm}^{-1}$ has also been observed. Thus, besides the quinuclidine absorption (at 1886 and $2937 \mathrm{~cm}^{-1}$ ) and the characteristic stretching modes of the thiourea network (seen normally at 1095 and between 3169 and $3367 \mathrm{~cm}^{-1}$ ), a relatively intense absorption band at 2164 and $2800 \mathrm{~cm}^{-1}$ and a weak absorption at $549 \mathrm{~cm}^{-1}$ are clearly seen.

From the structure of the compounds discussed above, the occurrence of an anisotropic proton conductor is expected, where in at least one of the crystalline directions the charge will be transported by proton migrations. ${ }^{13}$ As shown in Table 2, electric conductivity along the channel axis is significantly higher than along a perpendicular axis, and both are much greater than in pellets obtained by compressing the microcrystalline powder. The observed anisotropy for $\mathbf{2}$ and $\mathbf{3}$ should correspond to the difference between migration in two directions, one along the channels and the other, somewhat more difficult, through the thiourea-halide network. A small amount of water, which is not detectable in either elemental microanalysis or TG measurements, is necessary to observe the electrical properties in these compounds. In fact, under vacuum or in an argon atmosphere the conductivity of the materials was so low that it could not be measured. Moreover, the presence of moisture is also necessary to obtain robust pressed pellets. In the absence of moisture, cohesiveness between the crystals is not enough to obtain self-supporting specimens, regardless of the applied pressure. In the case of single crystals, conductivity is also reversibly switched by the presence of water. The observed conductivities, however, appear to be independent of the degree of moisture. For that we suggest that in the case of large single crystals the role of the water is to repair defects in the relatively fragile lattice, allowing the appearance of macroscopic long-range effects..
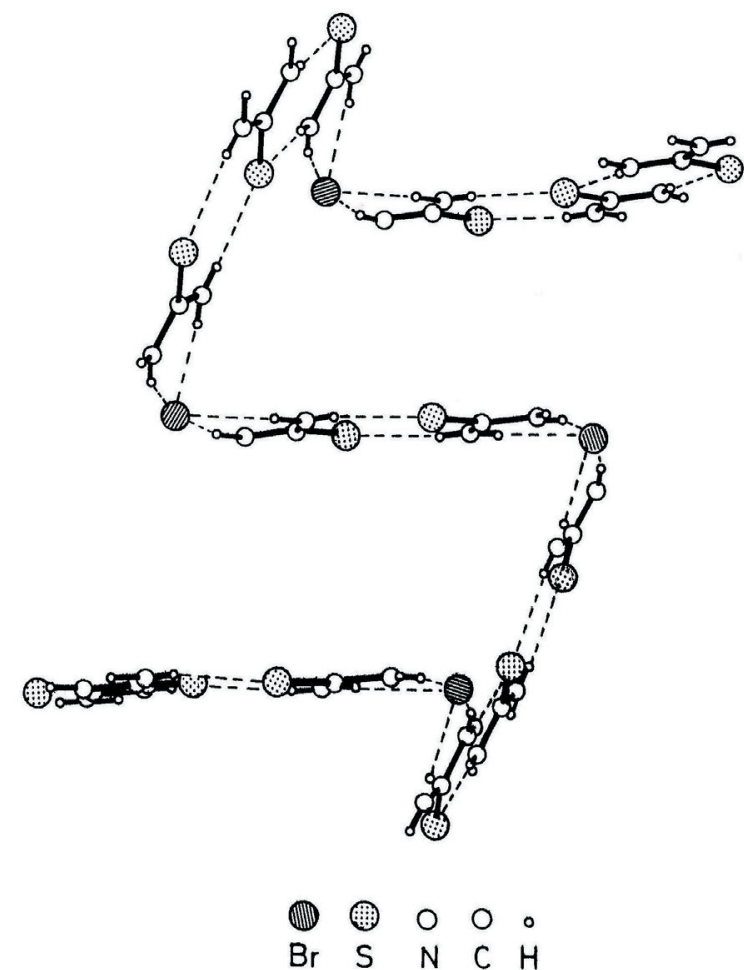

Figure 4: The way in which anionic chains, including halogenide ions build up through $\mathrm{N}-\mathrm{H}$...S and $\mathrm{N}-\mathrm{H}$...halide interactions, characteristic for $\mathbf{2}$, 3 and 4.

The Grotthuss mechanism can be applied to some extent to these 
systems, ${ }^{24,25}$ where water in the supramolecular compounds can be aligned forming polarized chains leading to an additional cooperative mechanism of the conductivity properties due to the presence of polarized water molecules. Proton transfer can produce an electric current when these water molecules instantly connect their fragments through the matrix network, as a result of which preferential conductivity properties in the parallel orientation are observed.

The conductivity difference found between $\mathbf{2}$ and $\mathbf{3}$ can be accounted for considering that the host cavity of $\mathbf{2}$ is surrounded by more electronegative chlorine atoms, resulting in a higher proton attracting effect in the parallel and perpendicular directions of the channel due of an ionic contribution.

In the powder samples all the reported values were determined by measurements parallel to the direction of the pressure applied by the mechanical press. All the conductivity values were obtained in vacuum $\left(10^{-2} \mathrm{mbar}\right)$ and under atmospheric pressure (Table 2).

The values of the conductivities for the pressed powder samples of compounds 1,2 and 3 in vacuum are very similar, and they behave as insulators $\left(10^{-11} \mathrm{~S} / \mathrm{cm}\right)$ (Table 2). However, the conductivity values of $\mathbf{2}$ and 3 under atmospheric conditions $\left(20^{\circ} \mathrm{C}, 1 \mathrm{~atm}\right), 10^{-8} \mathrm{~S} / \mathrm{cm}$, are higher that those corresponding to compound $\mathbf{1}$.

In the case of $\mathbf{4}$ the elemental unit of the anionic host network consists of hydrogen-bonded thiourea dimers bridged by iodide anions through N-H.....bonding, which defines ribbons running in the $c$ direction. These ribbons, which do not have any kind of direct interaction with each other, are aligned with their flat side parallel to the (110) set of planes (Figure 1c), leaving a free space of ca. $8.25 \AA$ where the diquinuclidinium cations $\left[\mathrm{Q}_{2} \mathrm{H}\right]^{+}$are located. However, there is no direct linkage between the anionic network and the embedded cations, so the interactions that occur are due to coulombic as well as van der Waals forces, in a manner similar to that of the other ternary inclusion compounds described. However, the diquinuclidinium ions are in alternate positions, following the crystallographic $c$ axis. The conductivity value under atmospheric conditions for this compound is higher than that of the powder samples of $\mathbf{2}$ and $\mathbf{3}$, and proton transfer through $\mathrm{N} . . . \mathrm{H}^{+}-\mathrm{N}$ from one diquinuclidinium ion to its neighbour is easier, probably due to the greater proximity between the diquinuclidinium guests. The importance of crystalline order for proton transport, commented above, is also seen in the dependence of conductivity on temperature. Single crystals of compounds $\mathbf{2}$ and $\mathbf{3}$ clearly show semiconductor behavior. Resistivity increases with increasing temperature, and this effect is somewhat more pronounced for parallel conductivity. In $\mathbf{2}$ electrical conductivity decreases to $4.08 \times 10^{-5} \mathrm{~S} / \mathrm{cm}$ at $40{ }^{\circ} \mathrm{C}$ and to $2.68 \times 10^{-5}$ $\mathrm{S} / \mathrm{cm}$ at $60^{\circ} \mathrm{C}$ in the parallel orientation, and in the perpendicular orientation it goes from $9.74 \times 10^{-7} \mathrm{~S} / \mathrm{cm}$ at $40{ }^{\circ} \mathrm{C}$ to $2.54 \times 10^{-7} \mathrm{~S} / \mathrm{cm}$ at $60{ }^{\circ} \mathrm{C}$. For 3 the conductivity decreases from $2.28 \times 10^{-7} \mathrm{~S} / \mathrm{cm}$ at $40{ }^{\circ} \mathrm{C}$ to $4.88 \times 10^{-9} \mathrm{~S} / \mathrm{cm}$ at 60 ${ }^{\circ} \mathrm{C}$ in the parallel orientation.

The activation energy of the thiourea-halide compounds was determined in the $25^{\circ} \mathrm{C}$ to $77^{\circ} \mathrm{C}$ temperature range (Table 3). The change in conductivity in the pellets with increasing temperature is not noticeable for $\mathbf{2}$ and $\mathbf{3}$. Thioureahalide systems measured in pellet form show a change in conductivity values when temperature increases. In fact, the conductivity of compound 4 at $77^{\circ} \mathrm{C}$ is $3.54 \times 10^{-6} \mathrm{~S} / \mathrm{cm}$ under atmospheric pressure. The temperature increase probably produces a greater separation of the matrix layers, resulting in a possible activation of proton transfer.

Table 3: Activation energy values of urea-halogen and thiourea-halogen systems

\begin{tabular}{|c|c|c|c|c|c|}
\hline \multirow{2}{*}{\multicolumn{2}{|c|}{ C.I. }} & \multicolumn{2}{c|}{ Pellets } & \multicolumn{2}{c|}{ Monocrystal } \\
\cline { 3 - 6 } & & $\begin{array}{c}\mathrm{Atm} \\
(\mathrm{eV})\end{array}$ & $\begin{array}{c}\text { Vac } \\
(\mathrm{eV})\end{array}$ & $\begin{array}{c}\| \\
(\mathrm{eV})\end{array}$ & $\begin{array}{c}\perp \\
(\mathrm{eV})\end{array}$ \\
\hline $\mathbf{1}$ & $\mathrm{Tu}_{3} \mathrm{Q}$ & 0.27 & 0.17 & --- & -- \\
\hline $\mathbf{2}$ & $\mathrm{Tu}_{2}\left[\mathrm{Q}_{2} \mathrm{H}\right]^{+} \mathrm{Cl}^{-}$ & 0.41 & 0.87 & 1.05 & 2.08 \\
\hline $\mathbf{3}$ & $\mathrm{Tu}_{2}\left[\mathrm{Q}_{2} \mathrm{H}\right]^{+} \mathrm{Br}$ & 1.18 & 0.58 & 0.76 & 0.63 \\
\hline $\mathbf{4}$ & $\mathrm{Tu}_{9}\left[\mathrm{Q}_{2} \mathrm{H}\right]_{2}{ }^{+} \mathrm{I}_{2}^{-}$ & 0.96 & 3.67 & -- & -- \\
\hline $\mathbf{5}$ & $\mathrm{U}_{5}\left[\mathrm{Q}_{2} \mathrm{H}\right]^{+} \mathrm{Cl}^{-}$ & 2.62 & 0.68 & --- & \\
\hline $\mathbf{6}$ & $\mathrm{U}_{2}\left[\mathrm{Q}_{2} \mathrm{H}\right]^{+} \mathrm{Br}$ & 0.70 & 1.41 & --- & -- \\
\hline $\mathbf{7}$ & $\mathrm{U}_{2}\left[\mathrm{Q}_{2} \mathrm{H}\right]^{+} \mathrm{I}^{-}$ & 0.58 & 0.37 & --- & --- \\
\hline
\end{tabular}

$\mathrm{Atm}=$ atmospheric pressure. $\mathrm{Vac}=$ Vacuum

Urea-Halogen System

The small size of the host urea channels does not allow the formation of typical binary inclusion compounds with quinuclidine, but in the presence of lithium halide in methanol it is possible to form ternary structures like those of 5,6 and 7.

Compound $\mathrm{U}_{5}\left[\mathrm{Q}_{2} \mathrm{H}\right]^{+} \mathrm{Cl}^{-} 5$ has a very singular structure, because the chloride ion participates in the matrix forming bridges in a different way than the other compounds in the homologous series (Figure 1d). This matrix can possibly be described as a bichannel without the central union. The conductivity value in this kind of compound is higher than that of its homologue with thiourea (compound 2), because in spite of having the same crystal system, the presence of the bichannel in the matrix structure probably allows in the same channel a greater proximity of the diquinuclidinium ions in the parallel direction.

The structures of $\mathrm{U}_{2}\left[\mathrm{Q}_{2} \mathrm{H}\right]^{+} \mathrm{Br}-6$ and $\mathrm{U}_{2}\left[\mathrm{Q}_{2} \mathrm{H}\right]^{+} \mathrm{I}^{-} 7$ may be described as polyanionic matrices consisting of chains of urea ribbons bonded to one another with halide ions forming layered structures (see Figure 1c). The layers and the halide ions are displaced relative to one another, facilitating the intercalation of the guest. The result is an empty space where the diquinuclidinium ions $\left[\mathrm{Q}_{2} \mathrm{H}\right]^{+}$ are located, and these ions do not interact directly either with the halogen of the matrix or with the oxygen atoms. ${ }^{2 c}$ This difference in the structure affects the electric conductivity. For example, under atmospheric conditions the conductivities of compounds $\mathbf{6}$ and $\mathbf{7}$ are one order of magnitude greater than that of compound $\mathbf{5}$ (Table 2).

In the urea-halogen systems in atmospheric pressure the change in conductivity with temperature is typical of materials showing semiconductor behaviour. Qualitative observations of increase of conductivity with temperature is associated with the increased disorder in the host and also with increasing proton transport. The decrease of the conductivity values in vacuum is due to the lower relativity humidity of the pellets. If we compare the values obtained for the urea-halogen system, the order under atmospheric pressure conditions is $6>5>7$. A possible explanation of this behaviour is that the presence of atmospheric moisture as an impurity in the crystals can facilitate and activate the occupation of the interlamellar space supplying the O-H bonding for the circulation of the protons.

\section{ACKNOWLEDGEMENTS}

The authors gratefully acknowledge the financial support of this work by FONDECYT (Projects 1050287 and 1040581), and by the Universidad of Chile (DID).

\section{REFERENCES}

1.- (a) K. Takemoto and N. Sonoda. Inclusion Compounds of Urea, Thiourea and Seleneurea, Inclusion Compounds. IJ.L. Atwood, J.E.D. Davies and D.D. MacNicol (Eds.) , Vol. 2, pp. 47-67, Academic Press, New York (1984).

(b) J. Merchán, N. Yutronic, M.T. Garland, R. Baggio. Supramol. Chem. 16 (2), 147, (2004).

(c) D. Braga, F. Grepioni. Acc. Chem. Res., 33, 601, (2000).

2.- (a) J-M. Lehn. Comprehensive Supramolecular Chemistry. J.L. Atwood, J.E.D. Davies, D.D. MacNicols, F. Vogte (Eds), Pergamon Press, Vol. 111, (1996).

(b) R. Bishop, I. Dance. Top. Curr. Chem., 149, 137, (1988).

(c) N. Yutronic, J. Merchán, G. González, M.T.Garland. J. Chem. Soc., Perkin Transaction, 2, 956, (2002).

3.- (a) D.M. Walba, N.A. Clark, H.A. Razavi. Inclusion Phenomena and Molecular Recognition. J.L. Atwood (Ed.), Plenum Press, New York and London, p. 81-92, (1990).

(b) H.U. Lenné. Acta Crystallogr., 7, 1, (1954).

(c) N. Yutronic, J. Merchán, P. Jara, V. Manríquez, O. Wittke and G. González. Supramol. Chem., 16 (2), 411, (2004).

4.- (a) M.D. Hollingsworth and K.D.M Harris, K.D.M. Comprehensive Supramolecular Chemistry: Solid State Supramolecular Chemistry: Crystal Engineering. D.D. MacNicols, F. Toda, R. Bishop (Eds.), Pergamon, Oxford, Vol. 6, p.177-232, (1996).

(b) K.D.M. Harris and J.M. Thomas. J. Chem. Soc. Faraday Trans., 86, 1095, (1990).

(c) N. Yutronic, J. Merchán, M.T. Garland, P. Jara. J. Incl. Phenom., 45, $51,(2003)$.

5.- (a) F. Vögtle. Supramolekulare Chemie. B. G. Teubner (Ed.), Stuttgart, p. 13-156, (1989).

(b) P. Jara, J. Merchán, N. Yutronic, G. González. J. Incl. Phenom., 36, 101, (2000).

6.- C.J. Pedersen, Science, 241, 536, (1988). 
7.- (a) A. E. Smith, Acta Crystallog., 5, 224, (1952).

(b) T.C.W. Mak and Q. Li. Advances in Molecular Structure Research. M. Hargittai and I. Hargittai (Eds.), JAI Press, Greenwich, Connecticut, Vol. 4, pp 151-225, (1988).

(c) T.C.W. Mak. J. Incl. Phenom., 8, 199, (1990).

8.- (a) M.F. Bengen. Chem. Abstr., 48, 11479c, (1954).

(b), Q. Li, T.C.W. Mak. J. Incl. Phenom., 35, 621, (1999).

(c) Q. Li, T.C.W. Mak. Acta Cryst., C52, 2830, (1996).

9.- (a) T. Weber, H. Boysen, F. Frey. Acta Cryst., B56, 132, (2000).

(b) C.K. Lam, T.C.W. Mak. Tetrahedron, 56, 6657, (2000).

10.- (a) P. Jara, N. Yutronic and G. González. J. Incl. Phenom., 22, 203, (1995).

(b) N. Yutronic, J. Merchán, V. Manríquez, G. González, P. Jara, O. Wittke, M.T. Garland. Mol. Cryst. Liq. Cryst., 374, 223, (2002).

11.- N. Yutronic, G. González, P. Jara. Bol. Soc. Chil. Quím., 37, 39, (1992).

12.- P. Jara, N. Yutronic, C. Nuñez, G. González. Bol. Soc. Chil. Quim., 39, 347, (1994).

13.- N. Yutronic, V. Manríquez, P. Jara, O. Wittke, G. González. Supramol. Chem., 12, 397, (2001)
14.- N. Yutronic, V. Manríquez, P. Jara, O. Wittke G. González, J. Merchán. J. Chem. Soc., Perkin Trans. 2, 1757, (2000).

15.- T.C.W. Mak, O.W. Lau, M.F.C. Ladd, D.C. Povey. Acta Crystallogr., Sect. B, 34, 1290, (1978).

16.- Q. Li, W.H. Yip, T.C.W. Mak. J. Incl. Phenom., 23 (3), 233 (1978).

17.- T.C.W. Mak, R.K. McMullan. J. Incl. Phenom., 6, 473 (1998).

18.- Xue, F.; Mak, T.C.W. Acta Cryst., B56, 142 (2000).

19.- J. Merchán, N. Yutronic, P. Jara, M.T. Garland and R. Baggio. J. Incl. Phenom., 55, 367 (2006).

20.- K.F. Purcell and J.C. Kotz. Inorganic Chemistry, W.B. Saunders Company (Ed), Philadelphia (1978).

21.- J. Roziere, C. Belin, M.J. Lehman. Chem. Soc., Chem. Commun., 38. (1982).

22.- P. Merlet, S.D. Peyerihoff, B.J. Buenker. J.Am. Chem. Soc., 94, 8301 (1972).

23.- P. Politzer, P.H. Reggio. J. Am. Chem. Soc., 94, 8308 (1972).

24.- C.J.T. Grotthus. Ann. Chim., LVIII, 54 (1806).

25.- E.P. Quigley, A.J. Emerick, D.S. Crumrine, S. Cukierman. Biophys J., 75, 2811 (1998) 